\title{
Quantitative evaluation of the relationship between physical parameters and building demolition or adaptation outcomes
}

\author{
Delaney McFarland ${ }^{1} \cdot$ Brandon Ross $^{1}$ (D) M. Z. Naser ${ }^{1} \cdot$ Rijk Blok $^{2} \cdot$ Patrick Teuffel $^{2}$
}

Received: 12 July 2021 / Accepted: 1 November 2021

(C) The Author(s) 2021

\begin{abstract}
Building adaptation and re-use can contribute to a circular and sustainable built environment, as existing buildings are adapted and the need for new construction materials is reduced. The "adaptability" of buildings has been widely studied; however, few of these studies are quantitative. This paper uses Artificial Neural Networks (ANN) and Logistic Regression (LR) models to explore relationships between the physical features of buildings and their demolition or adaptation outcomes. Source data were taken from 59 buildings that were either demolished or adapted in the Netherlands. After the models were created and validated, a series of sensitivity studies were conducted to evaluate relationships between physical parameters and building outcomes. The physical parameter with the strongest relationship to adaptation outcomes was demountability (ease of removal) of building service elements. The quantitative results were then compared to results from an adjacent qualitative study. The relationships observed from the quantitative sensitivity studies align well with the qualitative observations.
\end{abstract}

Keywords Adaptability $\cdot$ Artificial neural network $\cdot$ Logistic regression $\cdot$ Sensitivity study $\cdot$ Circular economy $\cdot$ Re-use

\section{Introduction}

A circular economy of the built environment is a topic of increasing interest to academics and practitioners. Mimicking processes observed in nature, circular economies are systems in which materials at the end of their service lives become resources for new growth [1]. Circular economy has also been defined as "a regenerative system in which resource input and waste, emission, and energy leakage are minimized by slowing, closing, and narrowing material and energy loops" [2]. From this definition, building adaptation, particularly as an alternative to demolition and new construction, can contribute to slowing resource input and waste in the built environment. Building demolition has negative impacts on the environment through material disposal [3]. This paper is founded on two notions. First, that existing buildings can be reused, thereby slowing material flow into landfills. And second, that new buildings can be designed

Brandon Ross

bross2@clemson.edu

1 Glenn Department of Civil Engineering, Clemson University, Clemson, SC 29634, USA

2 Built Environment, Eindhoven University of Technology, Eindhoven, Netherlands to facilitate future adaptation. Both notions contribute to a circular economy of the built environment.

Guides have been written about strategies to design buildings for future adaptation $[4,5]$, but there is a dearth of quantitative empirical studies that evaluate the effectiveness of the reported strategies [6]. This paper advances knowledge on adaptable building design by identifying physical features of buildings that have positive and negative relationships with adaptation and demolition outcomes. The quantitative models created through this study are an additional guide for stakeholders who wish to evaluate adaptability during the design phase of new buildings or during the service phase of existing buildings.

By supporting the design and analysis of adaptable buildings, this paper has the overarching goal of contributing to a sustainable and circular built environment. More specifically, this paper addresses three specific research questions:

1. Do physical parameters of buildings relate to demolition and/or adaptation outcomes?

2. If physical parameters are related to certain outcomes, which parameters are most significant?

3. Do the parameters related to demolition or adaptation outcomes also correspond to parameters that improve adaptability? In other words, do real-world adaptation 
outcomes correspond with design for adaptability strategies?

\section{Background}

\section{Design for Adaptability (DfA)}

Adaptability has been defined as "the ease with which a building can be physically modified, deconstructed, refurbished, reconfigured, repurposed and/or expanded" [7]. Similar definitions are discussed in the works by Pinder et al. [8] and Heidrich et al. [9]. Design for adaptability (DfA) is the intentional design of buildings so that they may be easily altered to support future needs [10]. DfA is preconfigured adaptability, i.e., it is adaptability that is embedded in a building during the design phase.

There are many strategies associated with DfA, but the quantitative effects of these strategies are largely unevaluated [6]. In a research effort that was run in parallel to the current paper, Rockow et al. [10] compared DfA strategies reported in the literature with empirical data from 89 building adaptation projects. The data were collected by asking practitioners about the buildings' physical features that facilitated or impeded adaptation. The thematic analysis method was used to identify overarching themes in the qualitative data. The themes are summarized in Table 1 and are used later in the current paper to address research question \#3. The themes reported in the table represent DfA strategies that have been empirically evaluated for effectiveness.

It is possible, and even common, for existing buildings to be adapted even if they were not intentionally designed using the DfA approach [10]. Furthermore, design is only one factor that contributes to adaptability. Social, political, legal, and economic factors are reported to influence adaptability and demolition/adaptation outcomes [10-12]. For example, historic status can be a driving factor in the decision to adapt a property instead of demolishing and rebuilding [11]. External factors are also critical when evaluating buildings in the context of a circular economy $[13,14]$. While the importance of external factors is acknowledged, the scope of the current paper is specifically focused on design-based factors.

\section{Measures of design-based adaptability}

Previous researchers have reported methods for measuring the adaptability that is associated with a building's physical parameters. This portion of adaptability has been called "design-based" because physical parameters are fundamental to a building's design [15]. Work on this topic by

Table 1 Themes from Rockow et al. [10]

\begin{tabular}{|c|c|}
\hline Theme & Characterizing Questions \\
\hline Plans & $\begin{array}{l}\text { Did the response discuss the quality or availability (or lack thereof) of as-built plans, models, or other documentation for } \\
\text { the building or project? }\end{array}$ \\
\hline Reserve & $\begin{array}{l}\text { Did the response indicate that the structure and or foundation were designed with sufficient load capacity and/or redun- } \\
\text { dancy to support the adaptation? Alternatively, did the responses indicate that the original structural design was less } \\
\text { than adequate for the adaptation? Planning ahead for future structural code requirements (or failure to do so) is also } \\
\text { included in this theme, as are responses discussing the general quality and adequacy of the existing structure. }\end{array}$ \\
\hline Layer & $\begin{array}{l}\text { Were the layers (structure, skin, services, etc.) separate from each other and easy to access and change? Were conflicts } \\
\text { between two or more layers mentioned? }\end{array}$ \\
\hline Open & $\begin{array}{l}\text { Did the response mention that the floor plan had large open spaces? Did they mention lack of obstructions that allowed } \\
\text { for large open spaces? Comments about general building size (e.g. "large building") were also included here. }\end{array}$ \\
\hline Floor-to-Floor Height & $\begin{array}{l}\text { Was the floor-to-floor height of the building mentioned? Did the floor-to-floor height prevent or create a challenge for } \\
\text { the addition of services? }\end{array}$ \\
\hline Simple & $\begin{array}{l}\text { Did the response reference the simplicity or complexity of building elements, systems, or the building as a whole? Was } \\
\text { the building repetitive and regular? Was the building footprint simple or complex? }\end{array}$ \\
\hline Material & $\begin{array}{l}\text { Did the response mention that the materials had toxins or hazards? Did the response indicate that the materials have } \\
\text { inherent quality and durability such that they might last for the building cycle and beyond? These responses were } \\
\text { related to both Design Features (e.g. initial selection of quality or low-quality materials) and Physical Condition (e.g. } \\
\text { present state of certain materials). }\end{array}$ \\
\hline Services & $\begin{array}{l}\text { Did the response discuss the presence or absence of existing building services adequate for the adaptation, or the ease } \\
\text { or difficulty with which new services could be added? Responses that specifically discussed floor-to-floor height or } \\
\text { layer separation issues were assigned to Floor-to-Floor Height and Layer, respectively. Note that these responses were } \\
\text { related to both Design Features (e.g. initial selection and installation of services) and Physical Condition (e.g. services } \\
\text { were too old). }\end{array}$ \\
\hline General Design & $\begin{array}{l}\text { This included responses that referenced building design but did not give enough details to be sorted into one of the } \\
\text { previous themes. }\end{array}$ \\
\hline
\end{tabular}


Landman [3], Blok and Teuffel [16], and Sattler et al. [17] each used the same dataset as the current paper.

In the thesis by Landman [3], data were collected on 60 multi-story buildings in the Netherlands that were demolished or adapted. A linear regression model was built from 64 parameters having to do with buildings' physical properties. The goal was to understand which of the building parameters were influential on the extended service life versus demolition of the building. Landman found that 14 of the parameters had an influence on the probability of extending the service life of a building.

The work by Blok and Teuffel [16] was based on data from Landman [3] and had a similar focus: identify parameters that influence the service life of a building. Their study used the data from Landman [3], linear regression and timeto-event analyses. They selected 20 parameters out of 64 that had the highest correlation with building outcomes, and from these identified the following as the most influential: sufficient space for services; sufficient loadbearing capacity and open spaces; column structure rather than bearing walls; a non-loadbearing façade; and access to vertical circulation.

In a case study, Sattler et al. [17] explored if and how the application of artificial intelligence (AI) can lead to a meaningful evaluation of existing building structures. The paper briefly outlines the possibilities to use AI in the decision-making process if buildings should be demolished or transformed.

Other works on measuring design-based adaptability include Becker et al. [18], Andrade and Bragança [19], Garaedts [20], and Ross [15]. Many of these used weightedsum models, the effectiveness of which was the focus of a paper by Becker et al. [18]. Becker et al. concluded that "The results [of the study supported] the reasonableness of using weighted-sum approaches to evaluate the adaptive potential of building designs". The current study also uses a weighted-sum model but uses a logistic function for the model, whereas previous work was all based on linear models.
Two recently published models focus specifically on plan layouts and their impact on adaptability. The Areal Openness Model (AOM) measures the "openness" (i.e. lack of obstruction) of a building floor plan [21]. As reported in Table 1, open plans are associated with greater adaptability. Another method, the Spatial Assessment of Generality and Adaptability (SAGA) method by Herthogs et al. [22], can be used to analyze floor plan layouts using graph theory. The SAGA and AOM methods are complementary to each other [23] and can be used to evaluate floor plans in much greater detail than is considered in the current paper.

\section{Building layering}

Layering of building systems is a critical concept in adaptable buildings and is referenced throughout the relevant literature. Although he did not call it "layering," Habraken was the first to recognize the importance of physically and functionally separating building systems as a means of facilitating future changes. His book Supports: An Alternative to Mass Housing proposed an approach in which a government agency provides a building structure, and individual occupants are responsible for creating the infill of their homes [24]. Expanding on this idea, Duffy encouraged designers to think of buildings as a system of layers with each layer having its own lifecycle [25]. Brand further expanded the idea and suggested six building layers: site, structure, skin, services, space plan, and stuff (Fig. 1) [26]. Through physical and functional separation of building layers, components of a layer can be replaced, maintained, or adapted without affecting the other layers. This is critical as layers tend to have differing replacement intervals (Fig. 1). Layering, as a means to design for adaptability, is supported by the empirical data and qualitative study reported by Rockow et al. [10] (Table 1).
Fig. 1 Building Layers (after Brand [26])

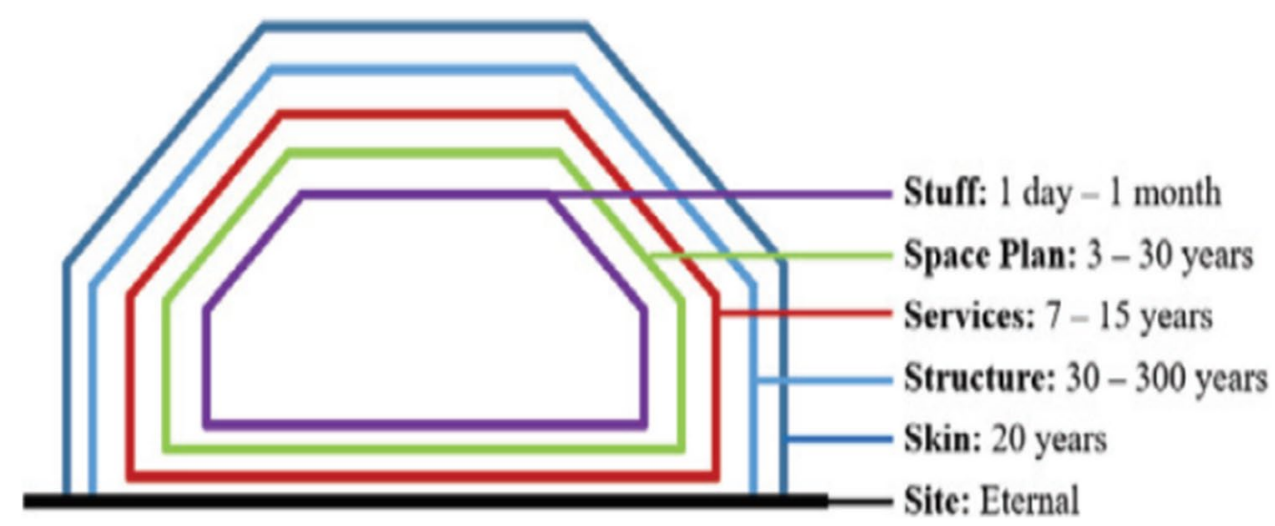




\section{Other studies comparing demolition and adaptation}

Table 2 lists previous studies of building demolition and adaptation outcomes. Methods and goals of the previous studies are summarized along with the distinction between the publication and the current paper. The use of quantitative methods, focus on buildings' physical features, and focus on lessons-learned for future design are common distinctions. As discussed in the previous paragraphs, the work by Landman [3] has particular relevance to the current paper. Landman collected the data and had similar goals to the current paper, though the distinction of the current paper is its use of Artificial Neural Networks and Logistic Regression models for analysis.

\section{Artificial neural networks}

An Artificial Neural Network (ANN) is a machine learning system that is intended to mimic the human brain. The ANN is fed with a training dataset that helps the system to "learn" patterns in the data. Once trained, a validation dataset is put through the ANN to evaluate the accuracy. Within the ANN, there are different layers processing the data: the input layer, the hidden layers, and the output layer. Each hidden layer contains a certain number of neurons, which are represented by the circles in Fig. 2. These neurons process the data and produce an output that is processed by the next hidden layer. The lines between neurons in Fig. 2 represent the flow of information between layers. The information passes between all the layers multiple times before reaching a final output.

ANN and other artificial intelligence methods can be effective for studying topics in the built environment. For example, Jonnalagadda et al. [32] used ANN to investigate the effects of skew and span length on prestressed concrete bridge deck and superstructure condition ratings. Naser et al. [33] utilized ANN and other machine learning methods to study reinforced concrete beams and their response in fires. These studies demonstrate the ability of ANN to analyze outcomes in the built environment that are dependent on complex relationships and interactions between variables. This ability makes ANN suitable for modelling the complex relationships between buildings' physical parameters and adaptation or demolition outcomes.

\section{Logistic regression}

Logistic regression (LR) models produce a sigmoidal or $\mathrm{S}$-shaped curve that describes the relationship between input and output variables, primarily in a binary fashion [34]. This feature makes LR well-suited to model the relationships between input variables and discrete outcomes, such as demolition or adaptation. Equation 1 is the generic form of an LR model. Each parameter $(X)$ is assigned a coefficient $(\beta)$ that weights the impact of the variable on the output. The equation includes an offset $(\alpha)$ that is analogous to the

Table 2 Previous publications comparing building demolition and adaptation outcomes

\begin{tabular}{|c|c|c|}
\hline Publication & Method/goal of publication & Distinction from current study \\
\hline $\begin{array}{l}\text { Landman [3] } \\
\text { Blok and Teuffel [16] }\end{array}$ & $\begin{array}{l}\text { Used linear regression modeling to identify parameters } \\
\text { related to adaptation or demolition outcomes }\end{array}$ & Linear regression and time-to-event modeling \\
\hline Rockow et al. [10] & $\begin{array}{l}\text { Used Thematic Analysis Method to compare DfA strate- } \\
\text { gies and empirical data from adaptation projects }\end{array}$ & Qualitative study \\
\hline Baker et al. [11] & $\begin{array}{l}\text { Examined case study adapt/demo projects to determine } \\
\text { drivers in decision making }\end{array}$ & $\begin{array}{l}\text { Qualitative study, included scope beyond buildings' } \\
\text { physical features }\end{array}$ \\
\hline Langston [12] & $\begin{array}{l}\text { Proposed the Adaptative Reuse Potential model for } \\
\text { evaluating existing buildings }\end{array}$ & $\begin{array}{l}\text { Studied existing buildings, not intended to aid in new } \\
\text { design, included scope beyond buildings' physical } \\
\text { features }\end{array}$ \\
\hline Damwijk [27] & $\begin{array}{l}\text { Proposed a framework for guiding adaptation and demo- } \\
\text { lition/new build decisions }\end{array}$ & $\begin{array}{l}\text { Studied existing buildings, not intended to aid in new } \\
\text { design, included scope beyond buildings' physical } \\
\text { features }\end{array}$ \\
\hline Alba-Rodriguez et al. [28] & $\begin{array}{l}\text { Compared the economic and environmental costs of } \\
\text { adaptation and demolition/new building }\end{array}$ & $\begin{array}{l}\text { Studied existing buildings, not intended to aid in new } \\
\text { design, included scope beyond buildings' physical } \\
\text { features }\end{array}$ \\
\hline Watson [29] & $\begin{array}{l}\text { Reviewed constraints to UK construction market and } \\
\text { proposed building adaptation as a path forward }\end{array}$ & $\begin{array}{l}\text { Not intended to aid in new design, included scope beyond } \\
\text { buildings' physical features }\end{array}$ \\
\hline Verster and Peters [30] & $\begin{array}{l}\text { Evaluated case studies of demolished and adapted } \\
\text { religious buildings in South Africa, with special focus } \\
\text { on physical features }\end{array}$ & $\begin{array}{l}\text { Qualitative comparisons, included scope specific to } \\
\text { religious buildings }\end{array}$ \\
\hline Crawford et al. [31] & $\begin{array}{l}\text { Reviewed technical models and case studies relating to } \\
\text { adaptation and demolition outcomes of social housing } \\
\text { in the UK }\end{array}$ & $\begin{array}{l}\text { Focused on cost and energy use, did not consider other } \\
\text { physical features }\end{array}$ \\
\hline
\end{tabular}


Fig. 2 ANN diagram

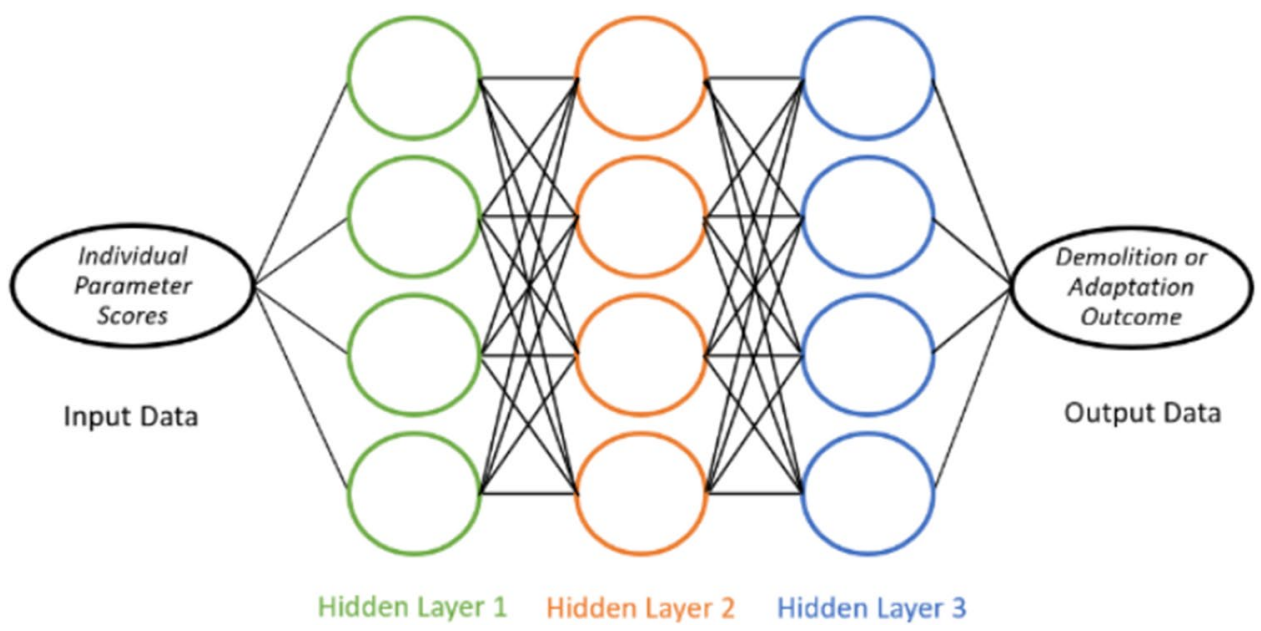

y-intercept of a Linear Regression model having $Y$ as the output.

$\log \left(\frac{Y}{1-Y}\right)=\alpha+\beta_{1} X_{1}+\cdots+\beta_{n} X_{n}$

As with ANN, LR modelling has also been applied to study topics in the built environment. One example is the work by Li et al. [35], who used LR models to study the relationships between the self-reported comfort level of building occupants and measures of their physiologic condition. Occupant skin temperature measured on a continuous scale was related to three discrete classifications of comfort: uncomfortably hot, comfortable, and uncomfortably cold. The current study uses LR modeling to relate numerical values that describe buildings' physical parameters with the discrete outcome of adaptation or demolition. The $\beta$ coefficient associated with each physical parameter provides an indication of how strongly the parameter is related to the buildings' outcomes.

\section{Methodology}

\section{Data collection}

The dataset for this study includes 39 adapted and 20 demolished buildings from the Netherlands between the ages of 21 and 114 years at the time that they were demolished or adapted. The buildings range in floor area from 2000 to $64,000 \mathrm{~m}^{2}$ and in height from 3 to 23 stories (Table 3). Occupancies were office (68\%), health care (12\%), industrial (10\%), academic buildings (8\%), and residential (2\%). All the buildings were from the same dataset used by Landman [3]. Some general criteria were applied when these buildings (adapted and demolished) were selected. Because the focus was on finding physical properties that could have influenced the decision of demolition versus adaptation,

\begin{tabular}{lll} 
Table 3 Building properties & & \\
\hline Parameter & Minimum & Maximum \\
\hline Size $\left(\mathrm{m}^{2}\right)$ & 2000 & 64,000 \\
Year Opened & 1895 & 1993 \\
Age at Change & 21 & 114 \\
\# of Stories & 3 & 23 \\
\hline
\end{tabular}

historical buildings were excluded, as laws in the Netherlands prohibit their demolition. Another criterion was the minimum size of the building. Buildings could be included if they had three or more stories and a minimum gross floor area of $2000 \mathrm{~m}^{2}$. Buildings were not excluded based on occupancy type, except for athletic facilities (as they often have fewer than three stories and have unusual structural layouts). They were all built between 1895 and 1993. Later buildings were not included because their ages would not have allowed sufficient time for the return of investments for the building owners.

Landman scored each parameter on a scale between 0 and 1. Values closer to 0 assumed increasingly stronger relationship with demolition; values closer to 1 assumed increasingly stronger relationship with adaptation. Scores were given as discrete values in 0.2 increments. Most parameters had qualitative definitions to guide scoring. In certain cases, such as floor-to-floor height, quantitative definitions were given to guide scoring. An example is shown in Table 4. Complete details of the system are reported by Landman [3].

The source documents and dataset were reviewed to perform spot-checks and to verify data fidelity. It was determined that the data were largely accurate and only a few subtle adjustments were made. Parameter scores in the final dataset are reported by McFarland [36]. The level of detail within the source documents and building plans varied. Around $80 \%$ of the buildings had a complete set of drawings, and data were easily readable. The other $20 \%$ were missing 
Table 4 Scoring of parameter "Ser_Dim_1"

Question: How much room is available within a raised floor or lowered ceiling?

\begin{tabular}{ll}
\hline Answer Choice & Parameter Score \\
\hline$<0.20 \mathrm{~m}$ & 0.0 \\
$0.20-0.40 \mathrm{~m}$ & 0.2 \\
$0.40-0.60 \mathrm{~m}$ & 0.4 \\
$0.60-0.80 \mathrm{~m}$ & 0.6 \\
$0.80-1.00 \mathrm{~m}$ & 0.8 \\
$>1.00 \mathrm{~m}$ & 1.0 \\
\hline
\end{tabular}

minor items, such as detail drawings or MEP drawings. One building's drawings were unreadable; therefore, the building was removed from the final dataset leaving 39 adapted buildings instead of 40 .

The original dataset included 62 building parameters. Based on the initial analysis by Landman [3], many of the parameters were reasoned to have a little or marginal relationship with the outcomes. For example, the quality of the acoustic insulation had little impact. To make the present study more tractable and focused, the number of parameters was reduced from 62 to 22 . The 22 retained parameters were consistent with those that Landman deemed important. Each of the remaining 22 is listed and described in Table 5. They have been sorted into the themes from Rockow et al. [10] by applying the characterizing questions presented in Table 1 . The physical meanings of the parameters in the Table 5 were re-worded slightly from the descriptions in the Landman thesis to provide clarity and convey their relationships to the themes. A few general parameters for each building were also retained in the final dataset, including occupancy, square footage, opening year, number of stories, and the age of the building at the time of the adaptation or demolition.

*The parameter could have also reasonably been associated with the "layer" theme.

\section{Overview of models and assessment of accuracy}

The ANN was created in MATLAB using the Neural Networks Toolbox [37], while the LR model was created using Excel and Xrealstats [38]. Based on the low number of data points and high number of building parameters in the dataset, the modelling was not conducted with the intention of producing statistically significant results, but to examine the relationships between parameters and outcomes. Thus, the models were used to address the first and second research questions pertaining to this work.

The final dataset was subdivided into a training set of 47 buildings $(\sim 80 \%)$ and a validation set of 12 buildings $(\sim 20 \%)$. Six demolished and six adapted buildings were
Table 5 The 22 parameters used in Landman [3] analyses and their relation to the themes from Rockow et al. [10]

\begin{tabular}{lll}
\hline Theme & Parameter & Physical Meaning \\
\hline Reserve & Str_Cap_4 & $\begin{array}{l}\text { magnitude of floor design live load } \\
\text { magnitude of roof design live load }\end{array}$ \\
Str_Cap_5 & feasibility of vertical expansion of structure \\
Layer & Str_Adj_1 & ease of disassembling structural elements from each other \\
& Str_Dem_1 & ease of disassembling floors from the structure \\
& Skin_Seg_1 & extent of integration between the façade and structure \\
& Skin_Seg_2 & extent of integration between the roofing and structure \\
& Skin_Dem_1 & ease of disassembling the façade from structure \\
& Skin_Dem_2 & ease of disassembling façade elements from each other \\
& Skin_Dem_3 & ease of disassembling the roof from the structure \\
& Spa_Dem_1 & ease of disassembling the internal walls \\
& Ser_Seg_1 & extent of integration between the services and structure \\
& Ser_Seg_2 & extent of integration between the services and skin \\
Str_Dim_2 & impact of gravity load resisting system on floor plan openness \\
Str_Dim_4 & horizontal grid spacing of the structure \\
Open & Str_Cap_1 & impact of the lateral force resisting system on floor plan openness \\
& Ser_Dim_1 & amount of space between ceiling and next floor \\
Str_Dim_3 & floor-to-floor height \\
Floor-to-Floor Height & Ser_Dem_1 & ease of disassembling of the service elements* \\
Services & Ser_Rea_1 & extent of access to the service elements \\
& Acc_Rea_3 & number and location of staircases in the building \\
Acc_Rea_4 & number and location of elevator shafts in the building \\
\hline & &
\end{tabular}


randomly selected for the validation set. The ANN and LR models were created using the training set and checked for accuracy using the validation set according to Eq. 2 .

Accuracy $=\frac{\text { total number of correct outputs }}{\text { total number of outputs }} * 100 \%$

\section{ANN model, Monte Carlo simulations, and sensitivity study}

The ANN was created in MATLAB through an iterative process. After a series of iterations and different combinations of the layer and neuron numbers, it was determined that the ANN consisting of three layers, with the first two layers having 15 neurons each, produced the most accurate results. Five epochs were used in the network with the best validation performance at 0.172 .

Once the ANN model was established, 30,000 Monte Carlo simulations were generated. Values for physical and general parameters in each simulation were taken from a random number generator and were uniformly distributed between the highest and lowest values in the source data. Rounding was used to align the randomly generated values with the discrete values used for parameter scoring. Each of the 30,000 simulated buildings was then input into the ANN and the outputs were recorded for a sensitivity study.

For the sensitivity study, the parameter scores from the simulated buildings were plotted vs. the ANN outputs. An example plot is shown in Fig. 3 for the "Ser_Dim_1" parameter. Similar plots were created for each parameter. The black dots in Fig. 3 represent individual simulations. For each parameter input value (vertical stack circled in the figure), there were approximately 2700 simulations. The average output for each level of parameter value was calculated; average values are represented by the blue diamonds in the figure. Linear trendlines were fit to the average values to evaluate sensitivity. The slope of the trendline represents how sensitive the overall outcome of the building is to that specific parameter, while the $\mathrm{R}^{2}$ value represents how well the trendline fits the average outputs. The $\mathrm{R}^{2}$ value was above 0.916 for $75 \%$ of the parameters, indicating that the Linear Regression models did a reasonable job of capturing the relationship between the average model outputs and the individual parameter scores. The process was repeated to determine the sensitivity associated with each parameter. Additional examples of the Monte Carlo simulations and plots are provided by McFarland [36].

\section{Logistic regression model and sensitivity study}

Creating the LR model and conducting the associated sensitivity study was a straightforward process. The training dataset was processed using the Xrealstats plugin for Excel [38]. The inputs for the LR model included the 22 parameters listed in Table 5. The general parameters were excluded because they were not on the 0 to 1 scale and including them prevented the model from converging to a sensible solution. Various options within Xrealstats were tried and found to have little effect on the resulting model. In the end, the "Solver" analysis type was used. The sensitivity study was conducted by comparing the model coefficients associated with each input parameter.
Fig. 3 Example parameter sensitivity plot for Ser_Dem_1

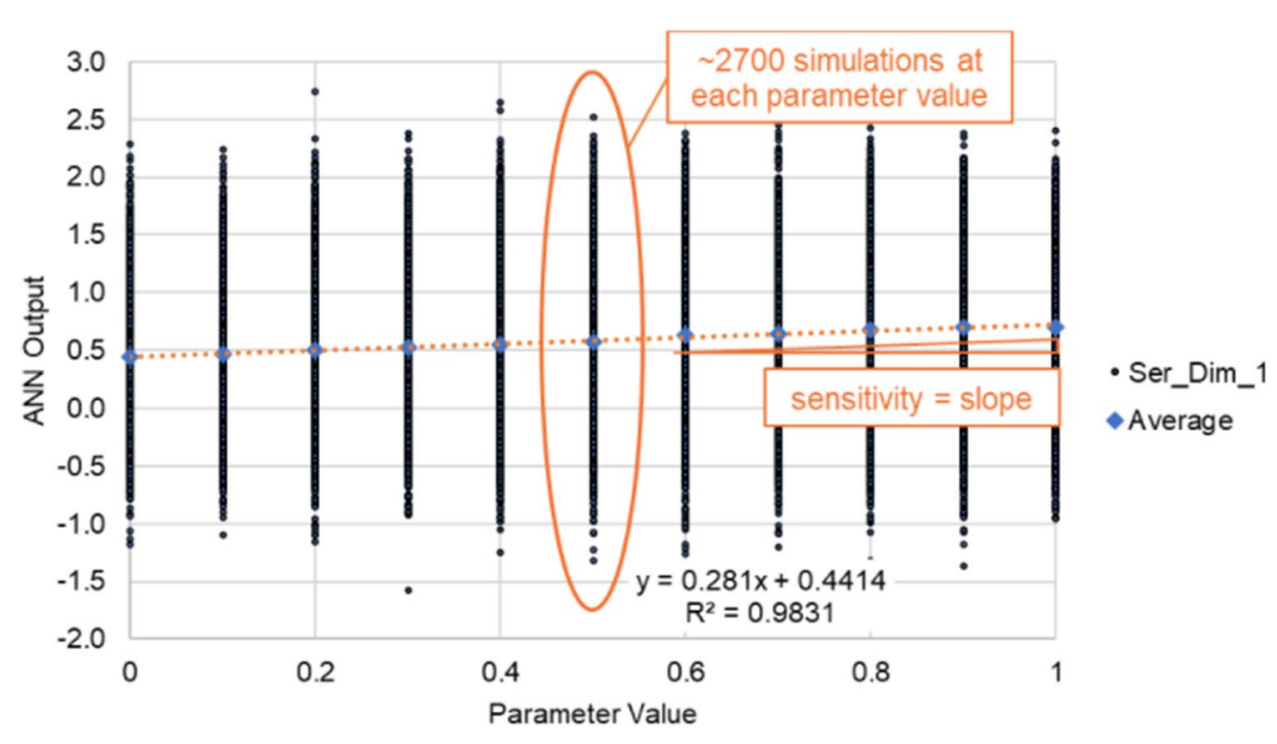




\section{Results and discussion}

\section{Model accuracies}

Accuracy of each model was determined according to Eq. 2. A classification cutoff value of 0.5 was used to interpret model results. This means that a model result above 0.5 was classified as an adaptation; values below 0.5 were classified as a demolition. Table 6 lists the accuracies of each model compared to validation set and the entire dataset. Accuracies are also listed separately based on demolition and adaptation outcomes. As seen in that table, the models were generally very accurate in characterizing the real-world outcomes. The lowest accuracy was $75 \%$ for the ANN in the validation dataset. When compared to the entire dataset, the ANN model accurately characterized the real-world outcome in $88 \%$ of the cases. The LR model was slightly less accurate overall at $85 \%$. The superior overall accuracy of the ANN was expected as the ANN is capable of accounting for interactions between the parameters. General parameters included in the source data for ANN were also likely to have contributed to the accuracy.

The models' degree of accuracy is notable considering that input data was almost exclusively physical parameters. While Rockow et al. [10] demonstrated a link between physical parameters and adaptability (i.e. the ease of making adaptations), it has also been reported that external factors are more significant than physical parameters when it comes to adapt/demolish decisions [11, 12, 29]. It appears that physical parameters of the sample buildings from the Netherlands played a more significant role than has been observed in the previous studies. This could partly be caused by the selection procedure applied, wherein the focus was on physical building properties themselves (excluding historical buildings and only including buildings of a minimum size, as described earlier in the Methodology section). One other possible explanation of these differing results may be that a link between physical parameters and demolition/ adaption outcomes is conditional upon the location and cultural engineering practices. If physical parameters affected the outcomes - as it appears that they did - then this link may be specific to the given sample of buildings from the
Netherlands and should not be extrapolated to other locations and collections of buildings.

\section{Relationships between parameters and outcomes}

Figure 4 shows a "tornado plot" of parameter sensitivities. Data in the plot come from the ANN model and Monte Carlo simulations. The parameters are ordered from the highest sensitivity at the top to the lowest at the bottom. The sensitivities in Fig. 4 have been normalized such that the highest sensitivity (Ser_Dem_1) is equal to 1.0. This parameter is associated with the ease of disassembling components of the building services.

Recall that the sensitivity of a parameter is equal to the slope of the linear trendline (e.g. Figure 3), and that higher slopes indicate greater sensitivity. Slopes of the trendlines are reported in Table 7 . Sensitivity values for some of the parameters are negative, indicating that a relationship with demolition/adaptation outcomes is the opposite of the assumption made by Landman when creating the scoring system [3]. An example is Str_Dem_2. For this parameter, the scoring system assumed that adaptation outcomes would be more likely if the floors could be easily separated from the rest of the structure. The relationship as determined by the ANN model was the opposite.

The sensitivity associated with general parameters is also reported in Fig. 4. For example, age had a positive relationship with adaptation, meaning that older buildings in the sample tended to be adapted instead of demolished. Inclusion of the general parameters in the ANN model and Monte Carlo simulations hedged their impact (if any) on the sensitivities reported for the physical parameters. In other words, the effects of any correlation between general parameters and outcomes are accounted for in the Monte Carlo simulations, and the sensitivities of the physical parameters are separated from general parameter correlations.

The LR model provides another means of evaluating parameter sensitivities. Figure 5 shows a tornado plot of the sensitivities from the LR model. Recall that the sensitivity values are determined by the $\beta$-coefficients for each parameter (Eq. 1). The sensitivity values shown in Fig. 5 are normalized to the $\beta$-coefficient for Ser_Dem_1. The LR and ANN results have notable similarities and differences.
Table 6 Accuracies measure for each model and dataset

\begin{tabular}{llllllll}
\hline Model & \multicolumn{3}{l}{ Accuracy } & & & & \\
\cline { 2 - 3 } & \multicolumn{2}{l}{ Validation Dataset } & & & \multicolumn{2}{l}{ Entire Dataset } & \\
\cline { 2 - 3 } \cline { 6 - 8 } & Demo & Adapt & Overall & & Demo & Adapt & Overall \\
\hline Artificial Neural Network & $75 \%$ & $75 \%$ & $75 \%$ & & $85 \%$ & $90 \%$ & $88 \%$ \\
Logistic Regression & $100 \%$ & $100 \%$ & $100 \%$ & & $70 \%$ & $92 \%$ & $85 \%$ \\
\hline
\end{tabular}


Fig. 4 Effect of individual parameters from the ANN

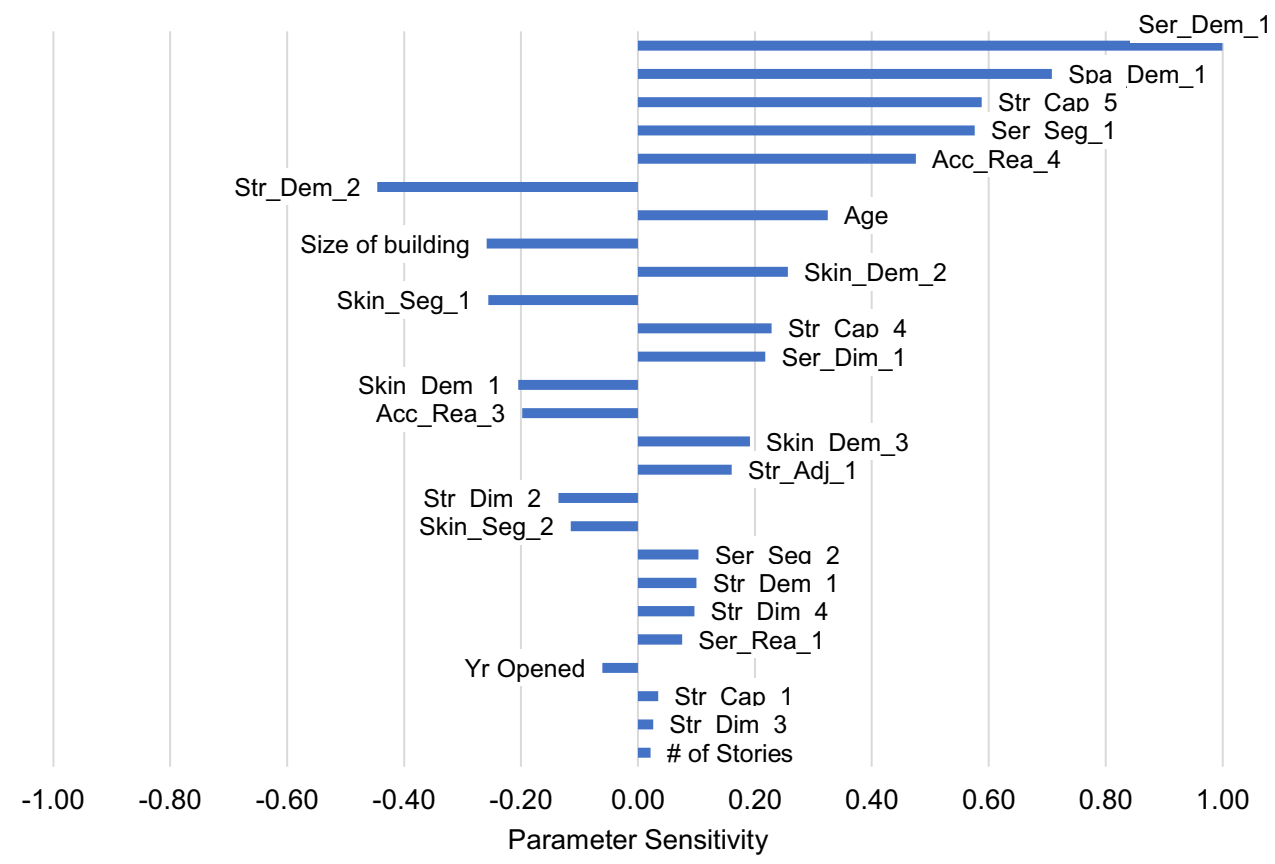

Table 7 Sensitivity values for all parameters for ANN and LR models

\begin{tabular}{|c|c|c|c|c|c|c|}
\hline \multirow[t]{2}{*}{ Parameter } & & \multicolumn{2}{|c|}{ ANN model } & \multicolumn{2}{|c|}{ LR model } & \multirow{2}{*}{$\begin{array}{l}\text { Average } \\
\text { Sensitiv- } \\
\text { ity }\end{array}$} \\
\hline & & Slope & Sensitivity & $\beta$ & Sensitivity & \\
\hline \multirow[t]{6}{*}{ Tier One } & Ser_Dem_1 & 1.29 & 1.00 & 20.72 & 1.00 & 1.00 \\
\hline & Str_Cap_5 & 0.76 & 0.59 & 9.55 & 0.46 & 0.53 \\
\hline & Spa_Dem_1 & 0.91 & 0.71 & 4.37 & 0.21 & 0.46 \\
\hline & Str_Cap_4 & 0.3 & 0.23 & 9.39 & 0.45 & 0.34 \\
\hline & Acc_Rea_4 & 0.61 & 0.47 & 2.65 & 0.13 & 0.30 \\
\hline & Ser_Dim_1 & 0.28 & 0.22 & 5.61 & 0.27 & 0.24 \\
\hline \multirow[t]{6}{*}{ Tier Two } & Ser_Rea_1 & 0.12 & 0.09 & 3.96 & 0.19 & 0.14 \\
\hline & Ser_Seg_2 & 0.13 & 0.10 & 3.02 & 0.15 & 0.12 \\
\hline & Str_Dim_4 & 0.1 & 0.08 & 3.67 & 0.18 & 0.13 \\
\hline & Str_Cap_1 & 0.04 & 0.03 & 4.21 & 0.20 & 0.12 \\
\hline & Str_Adj_1 & 0.21 & 0.16 & 0.15 & 0.01 & 0.09 \\
\hline & Str_Dim_3 & 0.03 & 0.02 & 1.34 & 0.06 & 0.04 \\
\hline \multirow[t]{9}{*}{ Tier Three } & Skin_Dem_1 & -0.26 & -0.20 & 11.13 & 0.54 & 0.17 \\
\hline & Ser_Seg_1 & 0.74 & 0.57 & -5.46 & -0.26 & 0.16 \\
\hline & Skin_Dem_3 & 0.25 & 0.19 & -1.49 & -0.07 & 0.06 \\
\hline & Skin_Dem_2 & 0.33 & 0.26 & -4.78 & -0.23 & 0.01 \\
\hline & Str_Dem_1 & 0.13 & 0.10 & -1.49 & -0.07 & 0.01 \\
\hline & Str_Dim_2 & -0.15 & -0.12 & 2.06 & 0.10 & -0.01 \\
\hline & Skin_Seg_2 & -0.18 & -0.14 & 2.09 & 0.10 & -0.02 \\
\hline & Str_Dem_2 & -0.57 & -0.44 & 7.66 & 0.37 & -0.04 \\
\hline & Acc_Rea_3 & -0.26 & -0.20 & 0.13 & 0.01 & -0.10 \\
\hline Tier Four & Skin_Seg_1 & -0.33 & -0.26 & -2.23 & -0.11 & -0.18 \\
\hline
\end{tabular}

Outcomes from both models had the greatest sensitivity to the Ser_Dem_1 parameter. Both models were also sensitive to "Str_Cap_5," which is a measure of the roof structural design criteria. Str_Dem_2, ease of dissembling the floor from the structure, is an example where the models had different sensitivities; this parameter was positively associated 
Fig. 5 Effect of individual parameters from the LR model

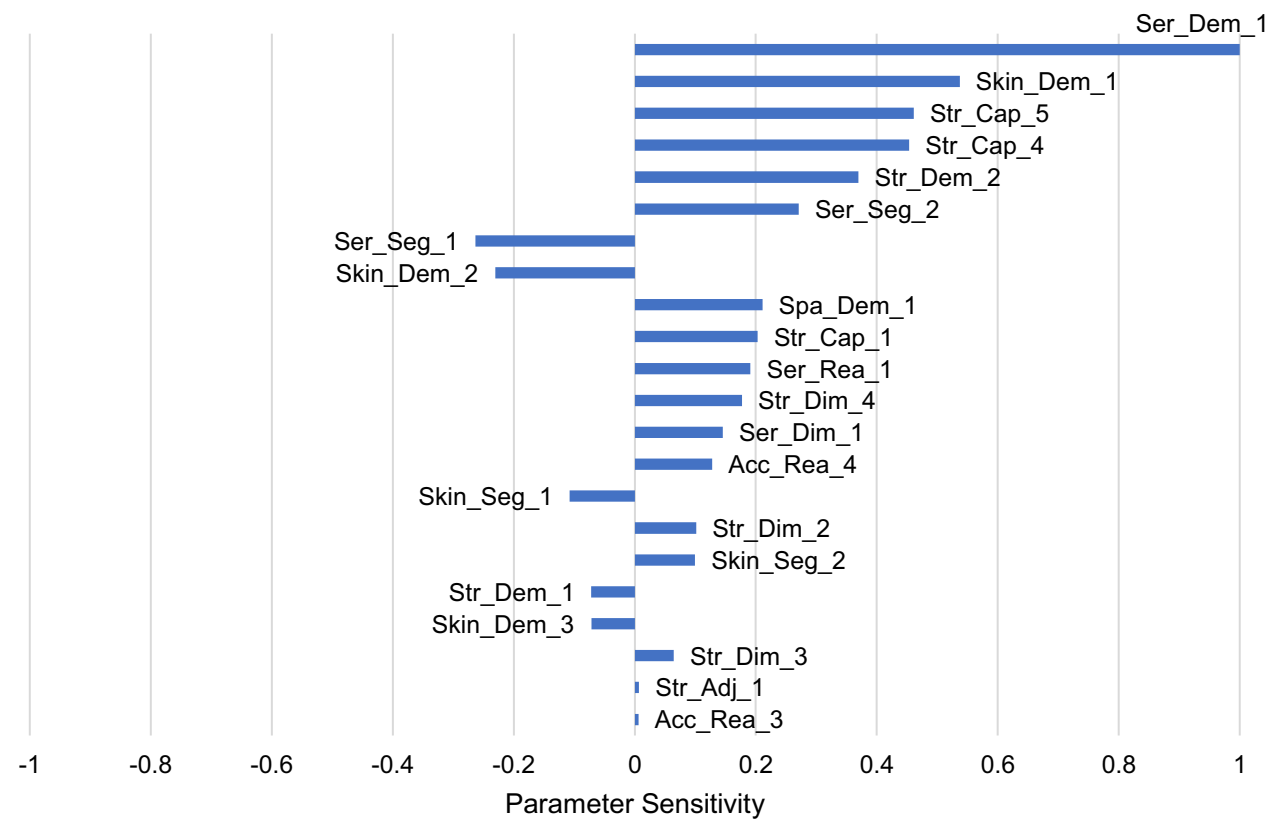

with adaptation in the LR model and negatively associated with adaptation in the ANN model.

To aid in interpreting the similarities and differences in model results, Table 7 combines results from both the ANN and LR models. The parameters were split into four different tiers based on (dis)agreement between models and average sensitivity. Parameters were in Tier One if both models had positive sensitivity and had average sensitivity of 0.24 or greater. Parameters in Tier Two also had positive sensitivity for both models but had average sensitivity values 0.14 or lower. The split between Tiers One and Two was based on the relatively large jump in average sensitivity between 0.24 and 0.14 . Parameters were classified in Tier Three if the ANN and LR had mixed sensitivity results (i.e. positive from one model, but negative from the other). Tier Four had only one parameter, Skin_Seg_1, which had negative sensitivity for both models.

While the overall accuracy of the models suggests that physical parameters were influential in the demolition/adaptation outcomes, caution is warranted when drawing conclusions about the influence of individual parameters. The paragraphs below discuss possible reasons for the observed relationships; however, causal relationships cannot be concluded from the quantitative analyses. It is possible that the observed results are particular to the small dataset and that different relationships would be observed in a larger sample of buildings. Caution is also warranted when comparing the numeric values of sensitivity. Each parameter was scored on its own scale and sensitivities are tied to that scale. Thus, small differences between parameter sensitivities are unlikely to be meaningful.
Referring to Table 7, it is noted that Ser_Dem_1, or the ease of disassembly of the service elements, had the highest sensitivity in both the ANN and the LR models. Less permanent service element connections, such as clamps or bolts, were strongly related to adaptation outcomes. Likewise, more permanent connections, such as in-situ poured concrete or fully grouted connections, were strongly related to demolition outcomes. It is wellestablished that building service elements are replaced at relatively fast rates (Fig. 1). Because services are replaced often, it is possible that the ease/difficulty of removing the service elements contributed to the demolition/adaptation decisions. Similar rationale can be applied to Spa_Dem_1 (ease of disassembling the internal walls) which relates to the often replaced or modified "space" layer (Fig. 1).

Str_Cap_5 (roof live load) and Str_Cap_4 (floor live load) were both in Tier One and suggest the importance of structural design criteria to adaptation. It is reasoned that structurally robust buildings are easier to adapt because they can support a variety of occupancies, and that robust structures have longer service lives and are more attractive for adaptation. Conversely, structurally weak buildings are not attractive for adaptation. There is anecdotal support for the importance of roof capacity as a facilitator for adding more occupiable space above the existing roof structure [39]. Thus, in addition to general structural robustness, it is possible that the opportunity of adding roof-top space contributed to the adaption outcomes.

Acc_Rea_4 is based on the number and location of elevator shafts. The sensitivity results indicate that adaptation outcomes were more common in buildings with multiple elevators distributed throughout the floor plan, while 
demolition outcomes were more common in buildings with a single centrally located elevator. Ser_Dim_1 is based on the amount of space between a ceiling and the next floor. It is reasoned that greater space allows more versatility in placing horizontal pipes, ductwork, and electrical conduits, and facilitates a wider range of floor plan layouts. Buildings with limited space for horizontal service runs restrict layout options and make adaptation more difficult.

Skin_Seg_1, extent of integration between the façade and structure, is unique among the parameters. Both the ANN and LR models resulted in negative sensitivity, meaning that the observed relationship between adaptation or demolition was opposite to that assumed by Landman [3]. Landman assumed that load-bearing facades would be more difficult to adapt and would be related to demolition outcomes. Conversely, she assumed that facades with few structural elements would be easier to adapt. One possible reason for the observed sensitivity of Skin_Seg_1 is that load-bearing concrete and masonry facades tend to be durable and have a relatively long service life, which makes such buildings more attractive for adaptation.

\section{Comparison of results with themes from Rockow et al. [10]}

An important distinction is noted between adaptability and adaptation outcomes. Adaptability is associated with the ease of adapting a building, whereas an adaptation outcome is a real-world event. The third research question of this paper is based on this distinction: Do the parameters that relate to demolition or adaptation outcomes also correspond to parameters that improve adaptability? This question is addressed by comparing the quantitative sensitivity results with the qualitative themes presented by Rockow et al. [10]. Recall that the themes were identified in empirical data from building adaptation projects, and each theme is an overarching concept found to have impacted the ease or difficulty (i.e. the adaptability) of the projects. Each physical parameter from the quantitative study was placed into one of the themes using the characterizing questions in Table 2. Parameters and the associated themes are presented in Table 5. Figure 6 shows the parameters and tiers associated with each theme.

In general, the themes reported by Rockow et al. that are associated with greater adaptability are consistent with the physical parameters from the current study that are related to adaptation outcomes. Physical parameters characterized in the Reserve, Floor-to-Floor Height, and Services themes were exclusively in Tiers One and Two. Thus, the importance of robust structures, sufficient vertical distance between floors, and special attention to building services were observed in both studies.

The Layer theme is effectively the same as the layering concept that is reported throughout the literature. Layering was a driving concept behind the Landman study [3], which is why Layer had the most associated parameters. The service and space plan layers change more frequently than the structure and skin layers (Fig. 1), and this seems to be a factor in how strong the relationships are between the associated parameters and building adaptation outcomes. In Rockow et al., building professionals observed that layering was important in the building adaptation process. Within the current dataset, eight out of the ten parameters associated with building layering produced mixed or negative results. These parameters are all associated with the structure or skin layers of a building, while the two parameters with strong positive relationships are associated with the service and space plan layers. This would seem to indicate that the interior space plan features of a building are more important to adaptability than those on the exterior.

Parameters associated with the Open theme had weak positive or mixed relationships with adaptation outcomes. Large horizontal structural grid spacing (Str_Dim_4) and
Fig. 6 Effect of themes on building outcomes

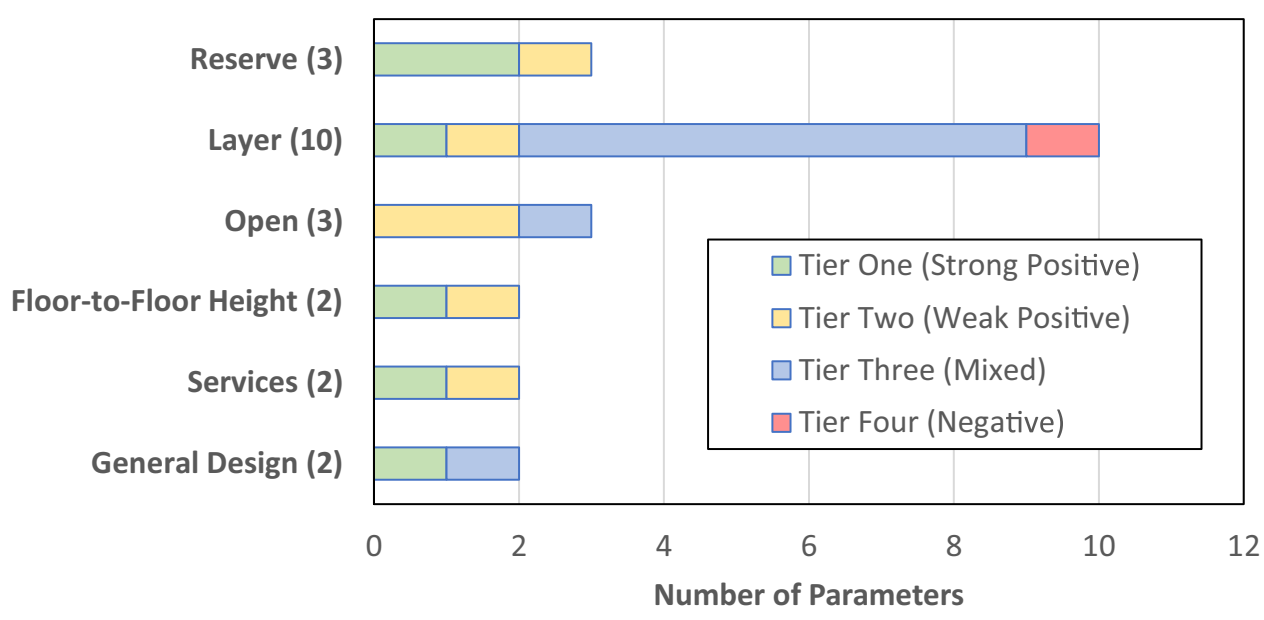


lateral force resisting system impact on openness (Str Cap_1) were both related to adaptation. Impact of the gravity load structural system on openness (Str_Dim_2) was the parameter with mixed results. The results regarding the Open theme are generally consistent with the current study and the Rockow et al. study; however, the relationships between openness and adaptation outcomes are not as strong as the relationship with some of the other themes.

The General Design theme in Rockow et al. was a "catchall" for items that did not fit squarely into the other themes. The two parameters for the current study that are characterized in the General Design theme are the number and location of stairwells and elevators. Stairs and elevators were not commonly mentioned in the Rockow dataset and comparisons with the current study are not meaningful.

The results of this study, then, lend credence to the idea that DfA strategies in the literature are indeed effective at increasing the adaptability of new building designs. This is significant because in order for the building industry to become circular, new buildings must be designed to accommodate future changes and avoid premature demolition. Designers, developers, and owners can use the DfA strategies discussed in this paper and many others to increase the adaptability of new building designs. In particular, the results of this paper suggest that over-designing the structure and increasing the floor-to-floor height are two straightforward ways to build-in adaptability. These strategies allow for different usages in the future, and for new services; both are critical components of many adaptation projects. In addition, designing services and interior walls to be easy to remove and replace seems to be a reliable way to increase adaptability. As discussed previously, space plans and services have relatively short service lives and need to be replaced frequently; if this is difficult, then adaptation is discouraged.

The results can also be useful for evaluating existing buildings for demolition or adaptation. An existing building that scores well in the ANN and LR models is a likely candite for adaption. Demolition may be the preferred option for a poor-scoring building.

\section{Summary and conclusions}

This paper used artificial neural network (ANN) and logistic regression (LR) models to study the relationships between building parameters and adaptation and demolition outcomes. Data were taken from a sample of 59 demolished or adapted buildings from the Netherlands. Sensitivity studies were performed to determine the strength and direction (positive or negative) of relationships between buildings' physical parameters and demolition/adaptation outcomes. The following paragraphs address the three research questions.
1. Do physical parameters of buildings relate to demolition and/or adaptation outcomes? Yes, for this dataset, the physical parameters of the buildings were related to the buildings' eventual adaptations or demolitions. The models were based on physical features of the buildings and were highly accurate in predicting their real-world outcomes. The ANN model was $88 \%$ accurate, while the LR was $85 \%$ accurate.

2. If physical parameters are related to outcomes, which parameters are most significant? Six of the physical parameters in the study had strong positive relationships with adaptation outcomes. Alternatively, it could also be said that they had strong negative relationships with demolition. The parameters and their calculated sensitivities are listed below:

- Ser_Dem_1 - ease of disassembling of the service elements (sensitivity $=1.00$ )

- Str_Cap_5 - magnitude of roof design live load (sensitivity $=0.53$ )

- Spa_Dem_1 - ease of disassembling the internal walls (sensitivity $=0.46$ )

- Str_Cap_4 - magnitude of floor design live load (sensitivity $=0.34$ )

- Acc_Rea_4 - number and location of elevator shafts in the building (sensitivity $=0.30$ )

- Ser_Dim_1 - amount of space between ceiling and next floor (sensitivity $=0.24$ )

The sensitivity values are a relative measure of how strongly the parameters are related to the demolition/adaptation outcomes. For reference, the other parameters had absolute sensitivity values of 0.18 or less. Values shown are normalized to the sensitivity of Ser_Dem_1.

3. Do parameters that impact demolition or adaptation outcomes correspond to parameters that improve adaptability? Rockow et al. [10] observed overarching themes in a qualitative dataset of building adaptation projects. These themes represent strategies and design features that contribute to adaptability. In general, the themes reported by Rockow et al. correspond to the physical parameters from the current study that are related to adaptation outcomes.

This study produced encouraging results regarding the potential of design to influence adaptation; however, the study also had notable limitations. The dataset only had 59 buildings. While this is the largest dataset of its kind, it only included a small sample of buildings in the Netherlands. Results cannot be considered representative of the Netherlands, and the results cannot be extrapolated to other 
countries. Larger datasets are needed to produce more convincing answers about the impact of physical parameters on adaptation and demolition. Future works are advised to consider to the influence of data quality and training procedure of AI models. For example, given the limited layout data points, the use of cross validation techniques can be explored. In addition, the use of topology-optimizers can be examined to arrive at optimal architecture of AI models.

What do the analyses in this paper practically tell us about building design and adaptation? It appears that physical parameters associated with buildings' services can be critical to adaptability and adaptation outcomes, and therefore also influential on the service life expectancy of buildings. Components of the building services are replaced at faster rates than other building layers, and this research suggests that designers should give specific attention to how the detailing and layout of services can accommodate future changes. Structural capacity should also be considered, as robust structures last longer and can facilitate a wider range of future building occupancies. Tall floor-to-floor heights and wide structural spacings are also important for creating adaptable space plans. It is worth noting that these ideas have been discussed previously in the literature in a qualitative manner. The novelty of the current study lies in its use of quantitative analyses to evaluate the positive relationship between adaptation and buildings' physical features.

Acknowledgements Material preparation and data were collected in a TU/e MSc. graduation project by Marijn Landman during an internship at and in close collaboration with Royal Haskoning DHV. Editing assistance of the final manuscript was provided by Anna Kate Becker.

Data availability Records held by a private company were used to collect data and are not available for sharing. Reduced data without identifiable information may be shared upon reasonable request.

Code availability Availability of codes is contingent on access to reduced project data; authors are willing to share the codes provided that data access is also granted.

Author's contributions Material preparation and data collection were guided by Rijk Blok and Patrick Teuffel. Data analysis and first draft of the manuscript were completed by Delaney McFarland as part of her MS program at Clemson University. Brandon Ross and M.Z. Naser provided guidance during data analysis. All authors contributed edits to the final version of the manuscript. All authors read and approved the final manuscript.

Funding Delaney McFarland and Brandon Ross were supported in this research by the United States National Science Foundation CMMI Award \#1553565.

\section{Declarations}

Conflicts of interest/competing interests The authors have no conflicts of interest to declare that are relevant to the content of this article.
Ethics approval Not applicable.

Consent to participate Not applicable.

Consent for publication Not applicable.

Open Access This article is licensed under a Creative Commons Attribution 4.0 International License, which permits use, sharing, adaptation, distribution and reproduction in any medium or format, as long as you give appropriate credit to the original author(s) and the source, provide a link to the Creative Commons licence, and indicate if changes were made. The images or other third party material in this article are included in the article's Creative Commons licence, unless indicated otherwise in a credit line to the material. If material is not included in the article's Creative Commons licence and your intended use is not permitted by statutory regulation or exceeds the permitted use, you will need to obtain permission directly from the copyright holder. To view a copy of this licence, visit http://creativecommons.org/licenses/by/4.0/.

\section{References}

1. Stahel WR (2016) The circular economy. Nature News 531(7595):435

2. Geissdoerfer M, Savaget P, Bocken NM, Hultink EJ (2017) The circular economy - a new sustainability paradigm? J Clean Prod 143:757-768

3. Landman, M. (2016). Technical building properties with the probability of elongating the functional service life (Master's thesis). Eindhoven University of Technology, Eindhoven

4. Kendall SH (2018) Healthcare architecture as infrastructure: open building in practice. Routledge

5. Schmidt R III, Austin S (2016) Adaptable architecture: theory and practice. Routledge

6. Rockow, Z. R., Ross, B., \& Black, A. K. (2019). Review of methods for evaluating adaptability of buildings. International Journal of Building Pathology and Adaptation

7. Ross BE, Chen DA, Conejos S, Khademi A (2016) Enabling adaptable buildings: results of a preliminary expert survey. Procedia Engineering 145:420-427

8. Pinder, J. A., Schmidt, R., Austin, S. A., Gibb, A., \& Saker, J. (2017). What is meant by adaptability in buildings?. Facilities

9. Heidrich O, Kamara J, Maltese S, Cecconi FR, Dejaco MC (2017) A critical review of the developments in building adaptability. International Journal of Building Pathology and Adaptation

10. Rockow ZR, Ross BE, Becker AK (2021) Comparison of building adaptation projects and design for adaptability strategies. J Archit Eng 27(3):04021022

11. Baker H, Moncaster A, Al-Tabbaa A (2017) Decision-making for the demolition or adaptation of buildings. Proc Inst Civil Eng Foren Eng 170(3):144-156

12. Langston, C. (2012). Validation of the adaptive reuse potential (ARP) model using iconCUR. Facilities

13. Pomponi F, Moncaster A (2017) Circular economy for the built environment: a research framework. J Clean Prod 143:710-718

14. Díaz-López C, Carpio M, Martín-Morales M, Zamorano M (2021) Defining strategies to adopt level (s) for bringing buildings into the circular economy. A case study of Spain. J Clean Prod 287:125048

15. Ross B (2017) The learning buildings framework for quantifying building adaptability. AEI 2017:1067-1077

16. Blok, R., \& Teuffel, P. (2019). Demolition versus transformation,"mortality of building structures" depending on their technical building properties. Paper presented at the IOP 
Conference Series: Earth and Environmental Science, 225(1), 012016

17. Sattler, A., Teuffel, P., Blok R., \& McFarland, D. (2021). Im bestand bauen und bestand erhalten. Nachhaltigkeit, Ressourceneffizienz Und Klimaschutz

18. Becker AK, Ross BE, Albright D (2020) Evaluating the weightedsum approach for measuring buildings' adaptability. Journal of Green Building 15(3):37-54

19. Andrade, J. B., \& Bragança, L. (2019). Assessing buildings' adaptability at early design stages. Paper presented at the $I O P$ Conference Series: Earth and Environmental Science, 225(1), 012012

20. Geraedts R (2016) FLEX 4.0, a practical instrument to assess the adaptive capacity of buildings. Energy Procedia 96:568-579

21. Rockow, Z. R., \& Ross, B. E. (2020). An areal openness model (AOM) for quantifying the "openness" of floor plans. International Journal of Building Pathology and Adaptation

22. Herthogs P, Debacker W, Tunçer B, De Weerdt Y, De Temmerman N (2019) Quantifying the generality and adaptability of building layouts using weighted graphs: the SAGA method. Buildings 9(4):92

23. Wilson, M., Ross, B., Herthogs, P., \& Rockow, Z. (2012). Comparison of two approaches for evaluating a floorplan's ability to change: SAGA and AOM. Sustainability in Energy and Buildings: Research Advances, (7), 1

24. Habraken, N. J., Valkenburg, B., \& Teicher, J. (1999). Supports: an alternative to mass housing

25. Duffy, F. (1990). Measuring building performance. Facilities

26. Brand S (1994) How buildings learn: what happens after they are built. Viking, New York

27. Damwijk, R. (2015). Comparing adaptation and demolition \& new build for office buildings in the newly developed ADNB indicator. TU Delft

28. Alba-Rodríguez MD, Martínez-Rocamora A, González-Vallejo P, Ferreira-Sánchez A, Marrero M (2017) Building rehabilitation versus demolition and new construction: economic and environmental assessment. Environ Impact Assess Rev 66:115-126
29. Watson $P$ (2009) The key issues when choosing adaptation of an existing building over new build. J Build Apprais 4(3):215-223

30. Verster, W., \& Peters, W. (2013). Adaptation versus demolition: the re-use of redundant places of worship in Bloemfontein, South Africa. Paper presented at the International Conference on Adaptation and Movement in Architecture, 10(12)

31. Crawford, K., Johnson, C., Davies, F., Joo, S., \& Bell, S. (2014). Demolition or refurbishment of social housing? A review of the evidence. UCL Urban Lab and Engineering Exchange

32. Jonnalagadda S, Ross BE, Khademi A (2016) A modelling approach for evaluating the effects of design variables on bridge condition ratings. J Struct Integ Main 1(4):167-176

33. Naser M, Hostetter H, Daware A (2020) AI modelling \& mapping functions: a cognitive, physics-guided, simulation-free and instantaneous approach to fire evaluation. SiF 2020:590-598

34. Peng CYJ, Lee KL, Ingersoll GM (2002) An introduction to logistic regression analysis and reporting. J Educ Res 96(1):3-14

35. Li D, Menassa CC, Kamat VR, Byon E (2020) HEAT-human embodied autonomous thermostat. Build Environ 178:106879

36. McFarland, D. (2021). Evaluation of physical parameters and building adaptation and demolition outcomes (Master's thesis). Clemson University, Clemson

37. Mathworks. (2020). Neural networks toolbox: User's guide (R2019a). http://cda.psych.uiuc.edu/matlab_pdf/nnet.pdf. Accessed Jan 2020 - Apr 2021

38. Zaiontz, C. (2012). Xrealstats (version 2012) [computer software]. Available at: https://www.real-statistics.com/free-download/realstatistics-resource-pack/. Accessed Jan 2020 - Apr 2021

39. Sarkisian M, Mathias N, Garai R, Lyrenmann J (2017) Historic Desmond building - a case study of an integrated retrofit. AEI 2017:578-590

Publisher's note Springer Nature remains neutral with regard to jurisdictional claims in published maps and institutional affiliations. 